\title{
The effect of intrauterine hypotrophy on the cardiovascular system of neonates
}

\author{
Patrycja Gazy ${ }^{1,2}$, Sylwia Marciniak², Helena Sławska², Anita Olejek², Bogdan Mazur ${ }^{1}$ \\ 'Department of Microbiology and Immunology, Medical University of Silesia in Katowice, Zabrze, Poland \\ 2Department of Neonatology, Medical University of Silesia in Katowice, Specialist Hospital No. 2 in Bytom, Poland \\ ${ }^{3}$ Department of Gynaecology, Obstetrics, and Gynaecological Oncology, Medical University of Silesia in Katowice, \\ Specialist Hospital No. 2 in Bytom, Poland
}

\section{ABSTRACT}

Intrauterine hypotrophy is an important, dangerous, and increasingly common complication of pregnancy. It is also the most common factor identified in cases of stillbirth. Intrauterine growth restriction plays a significant role in short- and long-term outcome and is associated with brain damage and neurodevelopmental impairment. Perinatal asphyxia is observed in $50 \%$ of the population of growth-restricted infants, who are also more prone to early complications such as intraventricular haemorrhage, necrotising enterocolitis, persistent pulmonary hypertension, hypoglycaemia, or hypothermia. There are also long-term consequences of intrauterine growth retardation, projecting into adult life, such as increased risk of cardiovascular disease, endocrine disorders, renal dysfunction, or metabolic syndrome. These observations are consistent with Barker's hypothesis, now referred to as the "developmental origins of health and disease". This article is a review of the literature regarding early and long-term complications as well as cardiovascular risk in this group of patients.

KEY WORDS:

hypertension, left ventricular hypertrophy, foetal growth retardation, foetal programming.

\section{BARKER'S HYPOTHESIS}

In 1990, Professor David J. P. Barker published a controversial (in those times) hypothesis of the foetal genesis of adulthood diseases [1]. He found the link between foetal growth and risk of cardiovascular disease. According to its assumptions, the shortage of nutrients and oxygen leads to permanent changes in the body of the foetus, having unfavourable consequences in adulthood. The exact molecular mechanisms are still unknown, but there are many correlations between unfavourable intrauterine conditions and changes in gene expression, signalling and metabolic pathways, abnormal mitochondrial function, and even epigenetic changes transmitted to subsequent generations, especially when occurring during critical periods of foetal development [2].

The structure and function of many important organs are changed, also due to the limitation of cell division as a response to an adverse intrauterine environment.

In addition to the direct impact of malnutrition on the slowdown of cell division, a significant role is also played by a reduced concentration of hormones affecting foetal growth, and therefore primarily insulin and growth hormone.

These modifications permanently adapt the newborn's organism to life in conditions of nutritional deficiencies; however, in the situation of proper supply of nutrients, they may lead to obesity, insulin resistance, type 2 dia-

\section{ADDRESS FOR CORRESPONDENCE:}

Patrycja Gazy, Department of Microbiology and Immunology, Medical University of Silesia in Katowice,

19 Jordana St., 41-808 Zabrze, Poland, ORCID: 0000-0002-7799-5830, e-mail: gazypatrycja@gmail.com 
betes, and the onset of metabolic syndrome [3]. Recent studies have shown the existence of these mechanisms also in the case of excessive nutrition - in newborns of obese mothers, and also in an animal model when using a high-fat diet in pregnant female rats [4].

Barker's hypothesis has opened a new avenue of research on the essence of adulthood diseases, mainly cardiovascular diseases, hypertension, diabetes, and dyslipidaemia. For years, further reports confirming the truth of the theory of "foetal programming" have been appearing in the literature, now referred to as "developmental origins of health and disease".

A model example of the effect of insufficient nutrition and hypoxia on the foetus is hypotrophy of the foetus, which for many years has been very popular with scientists proving the truth of Barker's hypothesis.

\section{FOETAL HYPOTROPHY}

Intrauterine growth restriction (IUGR) is a significant, dangerous, and increasingly common complication of pregnancy, which is also the most frequently observed pathology in pregnancies ending with stillbirth [5]. It is estimated that it occurs with varying frequency from $3 \%$ to $10 \%$ in developed countries; in poorly and medium-developed countries in 2010 the percentage of growth-restricted among all live-born newborns was 27\%, with the highest incidence in South Asia [6].

Intrauterine hypotrophy is a broad concept, in clinical practice the diagnosis is based on the finding of a birth weight below the $10^{\text {th }}$ percentile for gestational age. This group includes newborns constitutionally small in relation to gestational age and newborns in whom growth has been restricted due to adverse factors - maternal, foetal, environmental, and most frequently placental, so the newborn does not reach its growth potential.

The terms small for gestational age (SGA) and IUGR may overlap; however, they are not identical. A low birth weight may or may not be the result of inhibition of growth; in a similar way, a newborn with an intrauterine growth restriction may be born with a body weight above the $10^{\text {th }}$ percentile [7]. Appropriate diagnosis of the pathomechanism of foetal growth restriction is extremely important due to the determination of the risk of both early and late complications. The classification of intrauterine hypotrophy and literature evaluation is difficult due to the alternate use of SGA and IUGR concepts by many authors, and different inclusion criteria are also adopted. According to the WHO definition, foetal growth restriction is found when the birth weight is below the third percentile, while the ACOG assumes the limit of the $10^{\text {th }}$ percentile. The criterion of two standard deviations in relation to the average body weight is also accepted.

In prenatal ultrasound diagnostics, it is extremely important to detect abnormal growth of the foetus, and secondly distinguish healthy foetuses - constitutionally small from those exposed to adverse factors that led to growth restriction. In assessing the risk of IUGR complications, it is also important to assess the haemodynamic changes with the occurrence of redistribution and in more severe cases of circulatory centralisation as well as the distinction between early- and late-onset growth restriction. The boundary between early- and late-onset IUGR is the $32^{\text {nd }}$ week of pregnancy, as determined by a large cohort study [8]. The occurrence of IUGR below 32 weeks of gestation is most often associated with serious abnormalities of the placental function, thus increasing haemodynamic disturbances are observed, with increased placental resistance and foetal circulation redistribution, which also often contributes to the need for premature delivery. In this phenotype, IUGR is more often associated with preeclampsia and then in late-onset IUGR $(35.1 \%$ vs. $12.1 \%, p<0.001)$.

In contrast to early-onset, the late-onset IUGR is associated with mild placental dysfunction, less severe haemodynamic abnormalities, and is rarely associated with pregnancy-induced hypertension. Late-onset IUGR is also associated with an increased risk of both early and long-term complications, although less pronounced. The mortality rate is also significantly lower compared to foetuses diagnosed with foetal growth restriction before 32 weeks of gestation [9]. Early onset of IUGR, complicated by prematurity, is a high-risk factor for early complications - such as necrotising enterocolitis (NEC), intraventricular haemorrhages (IVH), or retinopathy of prematurity (ROP), mainly as a result of circulatory redistribution favouring vital organs - heart and brain. The study showed a significantly higher risk of IVH, ROP, and NEC in prematurely born infants with intrauterine growth restriction compared to premature babies born with age-adequate body weight [10].

This risk is greater in the case of a known pathological energetic triangle. This group includes newborns exposed to hypoglycaemia, hypoxia, and hypothermia in the first hours of life. In a study of 159 newborns divided into three groups: early preterm, late-preterm, and term, surprisingly, the most exposed to pathological energetic triangle was a group of late-preterm newborns [11].

IUGR foetuses are also more exposed to the occurrence of neurodevelopmental disorders, which can also affect small for gestational age newborns with normal umbilical artery Doppler [12].

Long-term consequences of intrauterine hypotrophy, which have an impact on adult life, increase the risk of cardiovascular diseases, endocrine disorders, kidney dysfunction, or metabolic syndrome. These observations are in line with Barker's hypothesis about the developmental genesis of adults' diseases, which are currently a major problem of our civilisation [13-15].

In 1984, an animal model study published by Jones et al. revealed significant differences between small vs. appropriate for gestational age in the function of the 
endocrine system. In the SGA group were observed to have lower concentration of glucose, insulin, and thyroid hormones. In this group hypocortisolaemia was also observed, but secretion of androstenedione and glucagon was elevated [16]. In group of growth-restricted foetuses a phenotype of progressive loss of $\beta$-cell mass and function was also observed $[17,18]$.

There were also disturbances in the axis of the growth hormone and insulin-like growth factors with a significantly lower insulin-like growth factor-1 secretion, and increased insulin-like growth factor-2 secretion in comparison with correctly growing foetuses [19]. Both IGF-1 and IGF-2 play an important role in embryogenesis of the myocardium. Expression of IGF-2 in the early phase of pregnancy is regulated by erythropoietin, secreted by hypoxic cells of the embryo before stimulation of the placenta, and as a result proliferation and differentiation of the myocardium cells is stimulated. In later stages of pregnancy, IGF-2 expression is regulated by the glucose and oxygen levels [20].

In growth-restricted compared to healthy neonates, predictors of cardiovascular complications such as endothelial dysfunction [21] and higher values of intima-media thickness (IMT), measured in the aorta wall, were observed [22]. Higher values of IMT were also correlated with high serum triglyceride concentration [23], and negatively correlated with IGF-1 concentration, in both healthy and hypotrophic newborns [24].

Growth restricted newborns are also at high risk of developing hypertension in later life, most likely due to a reduced number of nephrons, as well as abnormalities in the renin-angiotensin-aldosterone system and the function of tubular transporters [25]. The link between lower nephron number and hypertension was explain by the hyperfiltration theory of Brenner, in which lower nephron number results in a compensatory high glomerular filtration rate in each nephron and may lead to hypertension and renal injury [26]. In opposition to Barker's hypothesis, the multi-hits theory remains, which manifests foetal programming as a basis for the development of adulthood diseases on which the next strokes in the form of "catch-up growth" and incorrect diet during further development are superimposed. Some studies showed that the reduction in the number of nephrons alone is not sufficient to cause hypertension, whereas the previously described endothelial dysfunction, and in particular the main trigger, is the impairment of nitric oxide-dependent relaxation of the vessels [27].

In addition to metabolic, hormonal, and vascular changes that increase the risk of cardiovascular diseases, morphological changes in the structure of the myocardium itself and changes in systolic and diastolic function were also observed [28, 29].

This is probably the effect of haemodynamic changes with circulatory redistribution. As a result of hypoxia, the activity of the sympathetic nervous system increases, and this leads to increased peripheral resistance and reduction of the right ventricular preload. As a response to hypoxia, left ventricular inflow is significantly higher due to reflex vasodilatation of cerebral vessels. In the same mechanism, the coronary circulation is also increased. As a result of these changes, foetal left ventricular pre- and afterload are significantly higher than in normal physiological pregnancy [30], and this in turn leads to left ventricular overload.

Crispi et al. described the progression of subclinical foetal cardiac dysfunction and an increase in the activity of myocardial injury biomarkers, depending on the degree of intrauterine growth retardation, based on the three-step scale of blood flow in the umbilical artery in diastole (current/absent/reverse flow). Subclinical heart dysfunction was already observed in benign forms of IUGR, with marked progression with the degree of placental insufficiency. Heart function was evaluated based on cardiac output, E/A ratio on the mitral and tricuspid valves, end-diastolic dimension of the left and right ventricle, and the myocardial performance index (MPI) [31]. Two years later, Comas et al. demonstrated the existence of both systolic and diastolic heart dysfunction in this group of patients in a study using the tissue Doppler function [32].

Although, in these publications the cardiac output did not differ in the examined groups, based on the analysis of haemodynamic changes in foetal magnetic resonance imaging, the existence of redistribution of blood circulation, probably resulting from the response to hypoxia and the need to protect vital organs, and thus the brain, heart, and adrenal glands, which explains the increased flow through the superior vena cava in growth-restricted foetuses [33]. Similar conclusions were presented by Fouzas et al. in 2014. The authors, on the basis of advanced echocardiographic methods, showed in the IUGR newborns left ventricular dysfunction, ventricular septum hypertrophy. End-diastolic left ventricular volume was significantly higher in comparison with eutrophic newborns [34].

In 2013, Tsyvian et al. and later Sehgal et al. published the results of studies showing statistically more frequent occurrence of impaired heart relaxation in neonates small for gestational age, most likely as a result of chronic intrauterine hypoxia.

Studies have also shown that in intrauterine growth restricted newborns there is an adverse remodelling of the myocardium, with left ventricular hypertrophy $[35,36]$.

Myocardial remodelling and vascular changes were also described in a population of 80 intrauterine growth-restricted children with mean age of five years, compared to 120 healthy children. In the foetal growth-restricted (FGR) group globular cardiac shape and systolic and diastolic dysfunction were observed. Stroke volume, and systolic mitral and tricuspid annular plane systolic excursion were decreased both in mild 
and severe FGR [37]. These unfavourable effects were observed in both early- and late-onset IUGR newborns [38].

Myocardial remodelling was already observed at the cellular level. On the basis of experimental studies on an animal model, in foetuses with intrauterine growth restriction, changes in the structure of myocardial cells were demonstrated, which mainly concerned the left ventricle. The number of myocardium cells of the left ventricle was smaller, but with a larger volume compared to the right ventricle, as well as in relation to the control group. The number and length of the microcirculatory vessels of the left ventricle were also decreased [39].

Interestingly, the rodent model showed the effect of intrauterine growth restriction induced by uteroplacental insufficiency on left ventricular hypertrophy and developing of hypertension, not only in the first generation, but also in the next generation of rats, which were not exposed to placental insufficiency. These studies can confirm the important role of foetal programming [40].

\section{CONCLUSIONS}

IUGR is a very serious complication of pregnancy that adversely affects all aspects of the developing organism. So far, studies have demonstrated the effect of intrauterine growth restriction on the risk of early and late complications, as well as persistent epigenetic, metabolic, and hormonal changes that originally adapt the body to life in conditions of limited access to nutrients. However, normative or increased supply of protein, carbohydrates, and fat in the first years of life can lead to the development of various types of complications, including insulin resistance, metabolic syndrome, obesity, and type 2 diabetes, although there are also theories that foetal programming itself is not enough to induce late complications. It is, however, an important basis for an increased risk of adulthood diseases if it is joined by other unfavourable factors such as an intensified process of "catch up growth", incorrect diet profile, lifestyle, and drugs. It also seems to be an extremely important impact of growth restriction on myocardial remodelling, especially because there are studies describing changes in the structure and function of the myocardium not only in the early postnatal period, but also in middle childhood and in pre-schoolers born as SGA newborns. Further research on large groups of newborns with intrauterine growth restriction is needed, with long-term and several-year follow-up with echocardiographic evaluation of left ventricular structure and function.

All these described complications increase the risk of cardiovascular diseases and in relation to such burdens, and information about the perinatal period should always be taken into account in the interview; in the case of intrauterine hypotrophy, the patient should be given special care with instructions to the patient about prophylactic behaviour, the use of appropriate diet, lifestyle, physical exertion, and periodic blood pressure control.

\section{DISCLOSURE}

The authors declare no conflict of interest.

\section{REFERENCES}

1. Barker DJ. The fetal and infant origins of adult disease. BMJ 1990; 301: 1111.

2. Smith CJ, Ryckman KK. Epigenetic and developmental influences on the risk of obesity, diabetes, and metabolic syndrome. Diabetes Metab Syndr Obes 2015; 8: 295-302.

3. Berends LM, Dearden L, Tung YCL, et al. Programming of central and peripheral insulin resistance by low birthweight and postnatal catch-up growth in male mice. Diabetologia 2018; 61: 2225-2234.

4. Boney CM, Verma A, Tucker R, Vohr BR. Metabolic syndrome in childhood: association with birth weight, maternal obesity, and gestational diabetes mellitus. Pediatrics 2005; 115: 290-296.

5. Cosmi E, Fanelli T, Visentin S, et al. Consequences in Infants That Were Intrauterine Growth Restricted. J Pregnancy 2011; 2011: 364-381.

6. Lee ACC, Katz J, Blencowe H, et al. National and regional estimates of term and preterm babies born small for gestational age in 138 low-income and middle-income countries in 2010. Lancet Glob Health 2013; 1: 26-36.

7. Podsiadło B, Caus I, Naworska B, et al. Hipotrofia płodu - przyczyny, sposoby prowadzenia ciąży i rozwiązanie w materiałach II Kliniki Położnictwa i Ginekologii Śląskiej Akademii Medycznej w Katowicach. Klin Perin Gin 2007; 43: 61-64.

8. Savchev S, Figueras F, Sanz-Cortes M, et al. Evaluation of an Optimal Gestational Age Cut-Off for the Definition of Early- and Late-Onset Fetal Growth Restriction. Fetal Diagn Ther 2014; 36: 99-105.

9. Figueras F, Caradeux J, Crispi F, et al. Diagnosis and surveillance of late-onset fetal growth restriction. Am J Obstet Gynecol 2018; 218: S790-S802.

10. Garite TJ, Clark R, Thorp JA. Intrauterine growth restriction increases morbidity and mortality among premature neonates. Am J Obstet Gynecol 2004; 191: 481e7.

11. Mitrovic L, Mikovic Z, Markovic MV, Mihailovic S. Impact of transient period of metabolic adaptation on perinatal asphyxia in neonates with intrauterine growth retardation. J Matern Fetal Neonatal Med 2017; 30: 2665-2670.

12. Figueras F, Eixarch E, Meler E, et al. Small-for-gestational-age fetuses with normal umbilical artery Doppler have suboptimal perinatal and neurodevelopmental outcome. Eur J Obstet Gynecol Reprod Biol 2008; 136: 34-38.

13. De Boo HA, Harding JE. The developmental origins of adult disease (Barker) hypothesis. Aust N Z J Obstet Gynaecol 2006; 46: 4-14.

14. Barker DJP. Adult consequences of fetal growth restriction. Clin Obstet Gynecol 2006; 49: 270-283.

15. Barker DJP. In utero programming of cardiovascular disease. Theriogenology 2000; 53: 555-574.

16. Jones CT, Lafeber HN, Roebuck MM. Studies on the growth of the fetal guinea pig. Changes in plasma hormone concentration during normal and abnormal growth. J Dev Physiol 1984; 6: 461-472.

17. Mohan R, Baumann DC, Alejandro EU. Fetal undernutrition, placental insufficiency and pancreatic $\beta$-cell development programming in utero. Am J Physiol Regul Integr Comp Physiol 2018; 315 : R867-R878.

18. Bertin E, Gangnerau MN, Bellon G, et al. Development of $\beta$-cell mass in fetuses of rats deprived of protein and/or energy in last trimester of pregnancy. Am J Physiol Regul Integr Comp Physiol 2002; 283: R623-R630.

19. Jones CT, Lafeber HN, Rolph TP, Parer JT. Studies on the growth of the fetal guinea pig. The effects of nutritional manipulation on 
prenatal growth and plasma somatomedin activity and insulin-like growth factor concentrations. J Dev Physiol 1990; 13: 189-197.

20. Anversa P, Kajstura J, Cheng W, et al. Insulin-like growth factor-1 and myocyte growth: the danger of a dogma. Carciovasc Res 1996; 32: 484-495.

21. Yzydorczyk C, Armengaud JB, Peyter AC, et al. Endothelial dysfunction in individuals born after fetal growth restriction: cardiovascular and renal consequences and preventive approaches. J Dev Orig Health Dis 2017; 8: 448-464.

22. Skilton MR, Evans N, Griffiths KA, et al. Aortic wall thickness in newborns with intrauterine growth restriction. Lancet 2005; 365: 1484-1486.

23. Koklu E, Kurtoglu S, Akcakus M, et al. Increased aortic intima-media thickness is related to lipid profile in newborns with intrauterine growth restriction. Horm Res 2006; 65: 269-275.

24. Koklu E, Ozturk MA, Kurtoglu S, et al. Aortic intima-media thickness, serum IGF-I, IGFBP-3, and leptin levels in intrauterine growth-restricted newborns of healthy mothers. Pediatr Res 2007; 62: 704-709.

25. Baum M. Role of the kidney in the prenatal and early postnatal programming of hypertension. Am J Physiol Renal Physiol 2010; 298: F235-F247.

26. Brenner BM, Garcia DL, Anderson S. Glomeruli and blood pressure. Less of one, more the other? Am J Hypertens 1988; 1: 335-347.

27. Gacka E, Więcek A. Rola zjawiska programowania płodowego w rozwoju chorób cywilizacyjnych. Nadciśn Tętn 2012; 16: 63-74.

28. Crispi F, Miranda J, Gratacós E. Long-term cardiovascular consequences of fetal growth restriction: biology, clinical implications, and opportunities for prevention of adult disease. Am J Obstet Gynecol 2018; 218: S869-S879.

29. Crispi F, Crovetto F, Gratacos E. Intrauterine growth restriction and later cardiovascular function. Early Hum Dev 2018; 126: 23-27.

30. Krzeszowski W, Janiak K, Kalinka J, et al. Modern methods of monitoring fetuses with intrauterine growth restriction. Ginekol Pol 2016; 87: 135-142.

31. Crispi F, Hernandez-Andrade E, Pelsers MM, et al. Cardiac dysfunction and cell damage across clinical stages of severity in growth-restricted fetuses. Am J Obstet Gynecol 2008; 199: 254.e1-8.

32. Comas M, Crispi F, Cruz-Martinez R, et al. Usefulness of myocardial tissue Doppler vs. conventional echocardiography in the evaluation of cardiac dysfunction in early-onset intrauterine growth restriction. J Obstet Gynecol 2010; 203: 45.1-7.

33. Zhu MY, Milligan N, Keating S, et al. The hemodynamics of late-onset intrauterine growth restriction by MRI. Am J Obstet Gynecol 2016; 214: 367.1-367.

34. Fouzas S, Karatza AA, Davlouros PA, et al. Neonatal cardiac dysfunction in intrauterine growth restriction. Pediatr Res 2014; 75: 651-657.

35. Tsyvian P, Malkin K, Artemieva O, Wladimiroff JW. Assessment of left ventricular filling in normally grown fetuses, growth-restricted fetuses and fetuses of diabetic mothers. Ultrasound Obstet Gynecol 1998; 12: 33-38.

36. Sehgal A, Doctor T, Menahem S. Cardiac function and arterial biophysical properties in small for gestational age infants: postnatal manifestations of fetal programming. J Pediatr 2013; 163: 12961300.

37. Crispi F, Bijnens B, Figueras F, et al. Fetal growth restriction results in remodeled and less efficient hearts in children. Circulation 2010; 121: 2427-2436.

38. Demicheva E, Crispi F. Long-Term Follow-Up of Intrauterine Growth Restriction: Cardiovascular Disorders. Fetal Diagn Ther 2014; 36: 143-153.
39. Schipke J, Gonzalez-Tendero A, Cornejo L, et al. Experimentally induced intrauterine growth restriction in rabbits leads to differential remodelling of left versus right ventricular myocardial microstructure. Histochem Cell Biol 2017; 148: 557-567.

40. Master JS, Zimanyi MA, Yin KV, et al. Transgenerational left ventricular hypertrophy and hypertension in offspring after uteroplacental insufficiency in male rats. Clin Exp Pharmacol Physiol 2014; 41: 884-890. 